

\title{
KOMPARASI PRODUKSI DAN PENDAPATAN PETANI TEBU MITRA DAN NON MITRA PABRIK GULA RENDENG DI KABUPATEN KUDUS
}

\section{(Production and Income's Comparative Analysis of Sugarcane Partner Farmer and Non Partner Farmer of PG Rendeng, in Kudus Regency)}

\author{
Annisa Dyah Kumalasari, Kustopo Budiraharjo, Agus Setiadi \\ Program Studi S1 Agribisnis, Fakultas Peternakan dan Pertanian \\ Universitas Diponegoro, Tembalang, Semarang 50275 - Indonesia \\ Email : adkumalasari@gmail.com
}

Diterima 28 Desember 2018, disetujui 26 April 2019

\begin{abstract}
ABSTRAK
Penelitian ini bertujuan untuk menganalisis komparasi produksi petani tebu mitra dan non mitra, menganalisis komparasi pendapatan per bulan petani tebu mitra dan non mitra dengan Upah Minimum Kabupaten/Kota (UMK) Kudus, menganalisis komparasi pendapatan petani tebu mitra dan non mitra PG Rendeng di Kabupaten Kudus. Penelitian ini dilaksanakan pada Januari hingga Maret 2018 di Kecamatan Jekulo, Gebog dan Dawe, Kabupaten Kudus. Metode penelitian yang digunakan pada penelitian ini ialah survai. Penentuan jumlah sampel menggunakan metode quota sampling dengan jumlah sampel 30 petani tebu mitra dan 30 petani tebu non mitra. Metode pengambilan sampel dilakukan dengan simple random sampling. Analisis data yang digunakan ialah analisis pendapatan, uji beda One Sample $t$ Test, Mann Whitney, dan Independent Sample t Test. Hasil penelitian menunjukkan bahwa tidak terdapat perbedaan antara produksi tebu petani mitra dan non mitra. Terdapat perbedaan pendapatan per bulan petani tebu mitra dan non mitra dengan UMK Kudus. Terdapat perbedaan antara pendapatan per hektar per tahun petani tebu mitra dan non mitra. Kemitraan dapat meningkatkan pendapatan petani, dengan jumlah produksi yang tidak jauh berbeda petani tebu mitra memperoleh pendapatan lebih tinggi daripada petani tebu non mitra.
\end{abstract}

Kata Kunci : mitra, non mitra, produksi, pendapatan, petani tebu,

\begin{abstract}
This study was aimed to analyze the comparative production of partner and non-partner sugarcane farmers, analyze the comparative income per month of partner and non-partner sugar cane farmers with the Minimum Wages of Kudus Regency, analyze the income comparison of partners and non-partners sugarcane farmers of PG Rendeng in Kudus Regency. This research was held in January until March 2018 in the Districts of Jekulo, Gebog and Dawe, Kudus Regency. This research method used survey method. Determination of the sample was using quota sampling method. The sample consists of 30 partner and 30 non-partner sugar cane farmers. The sampling method of this study was simple random sampling. The data was analyzed with income analysis, One Sample t Test, Mann Whitney, and Independent Sample t Test. The results of the study showed that there is no difference between sugar cane production of partner and non-partner farmers. There was a differences in income per month for partners and non-partners sugarcane farmers with minimum wages of Kudus Regency. There was a difference between income per hectare per year for partners and non-partners sugarcane farmers.
\end{abstract}


Partnerships could increase farmers' income, with not much different of production, partner sugarcane farmers was earned higher income than non-sugarcane farmers.

Keywords : sugarcane farmer, partner, non-partner, production, income

\section{PENDAHULUAN}

Tanaman tebu (Saccharum officinarum) adalah salah satu komoditas nasional yang merupakan bahan baku pembuatan gula. Saat ini pemerintah tengah menggalakkan penanaman tebu supaya produksi gula Indonesia meningkat dan mencapai swasembada kembali, mengingat Indonesia pernah menjadi negara pengekspor gula (Suwarto et al., 2014). Seperti yang kita ketahui gula merupakan salah satu dari sembilan kebutuhan pokok (sembako) masyarakat Indonesia, oleh karena itu tanaman tebu menjadi sangat penting keberadaannya.

Jawa Tengah menjadi salah satu provinsi yang mempunyai produksi tebu paling tinggi kedua setelah provinsi Jawa Timur. Kabupaten Kudus merupakan salah satu dari lima penyumbang produksi terbesar di Jawa Tengah, tercatat pada tahun 2017 produksi tebu di Jawa Tengah mencapai 294.031,48 ton per tahun (Badan Pusat Statistik, 2018). Selain produksi tebu yang tinggi, di Kudus juga terdapat Pabrik Gula Rendeng yang dikelola oleh PTPN IX yang sudah ada sejak zaman Belanda. Keberadaan pabrik gula di Kabupaten Kudus menjadi salah satu alternatif untuk petani tebu dalam memperoleh pendapatannya yaitu dengan menyalurkan hasil panennya ke pabrik gula.

Pendapatan merupakan salah satu indikator yang menunjukkan kesejahteraan petani.Tingkat kesejahteraan petani tergolong baik apabila pendapatannya lebih besar dari Upah Minimum Kota/Kabupaten setempat atau yang biasa disebut UMK (Sadikin dan Subagyono, 2008). Upah Minimum Kota/Kabupaten sendiri merupakan upah yang besarnya ditentukan oleh Dewan Perupahan di masing-masing kota/kabupaten berdasarkan perhitungan kebutuhan minimum (Zen dan Hutagalung, 2007). Oleh karena itu, apabila pendapatan yang diperoleh dapat memenuhi atau bahkan melebihi kebutuhan petani, maka dapat dikatakan petani tersebut sejahtera.

Terdapat beberapa cara untuk meningkatkan kesejahteraan petani salah satunya yaitu dengan melakukan kemitraan. Kemitraan harus dapat menguntungkan kedua belah pihak dan tidak memberatkan salah satu pihak. Usahatani tebu di Indonesia kebanyakan diusahakan oleh petani tebu rakyat, dalam pemasaran petani tebu rakyat biasanya bekerjasama dengan pabrik gula. Ini merupakan salah satu bentuk kemitraan yang dijalin oleh petani tebu. Namun, tidak semua petani bersedia bermitra dengan pabrik gula karena alasan tertentu. Petani tebu yang bermitra akan mendapatkan beberapa fasilitas yang petani non mitra tidak dapatkan. Perbedaan fasilitas ini akan mempengaruhi pendapatan dan produksi petani tebu. Oleh karena itu dengan adanya penelitian ini akan diketahui perbedaan tingkat pendapatan dan produksi petani tebu yang bermitra dan yang tidak bermitra (Anriza, 2017).

Penelitian ini bertujuan untuk menganalisis perbandingan produksi petani tebu yang bermitra dengan pabrik gula dengan petani yang tidak bermitra dengan pabrik gula, menganalisis perbandingan pendapatan petani tebu mitra dan non mitra dengan UMK Kabupaten Kudus, dan menganalisis perbandingan pendapatan petani tebu yang bermitra dengan pabrik gula dengan petani yang tidak bermitra dengan pabrik gula dengan Upah Minimum Kabupaten Kudus.

\section{METODE PENELITIAN}

Penelitian dilaksanakan pada Bulan Januari - Maret 2018 di Kabupaten Kudus, Jawa Tengah. Responden pada penelitian ini terdiri dari petani tebu mitra dan non mitra di 
Kecamatan Gebog, Kecamatan Jekulo, dan Kecamatan Dawe. Kecamatan tersebut dipilih karena merupakan penghasil tebu terbanyak di Kabupaten Kudus.

Metode yang digunakan pada penelitian ini ialah survai. Metode survai adalah metode untuk mengumpulkan informasi dari responden dengan menggunakan kuesioner (Singarimbun dan Effendi, 2006). Metode penentuan jumlah sampel yang digunakan dalam penelitian ini ialah quota sampling. Quota sampling ialah dimana jumlah sampel yang diambil sesuai dengan jumlah (kuota) yang diinginkan dengan karakteristik tertentu (Morissan, 2012). Metode ini dipilih karena jumlah populasi yang tidak diketahui. Jumlah sampel yang diambil sebanyak 60 responden yang terdiri dari 30 petani mitra dan 30 petani non mitra dari Kecamatan Gebog, Dawe, dan Jekulo. Masing-masing kecamatan tersebut diambil sampel sebanyak 10 responden petani mitra dan 10 petani non mitra. Metode pengambilan sampel pada penelitian ini menggunakan metode simple random sampling. Simple random sampling merupakan suatu metode pengambilan sampel yang dilakukan secara acak karena anggota populasi dianggap homogen sehingga sampel dianggap dapat mewakili populasi (Sugiyono, 2016).

Analisis yang digunakan pada penelitian ialah analisis deskriptif kuantitatif. Analisis yang digunakan antara lain analisis pendapatan, analisis Independent Sample $t$ Test, dan analisis One Sample $t$ Test. Data yang diperoleh akan dianalisis sehingga diperoleh nilai pendapatan petani. Besarnya pendapatan petani tebu mitra dan non mitra dapat dihitung dengan rumus pendapatan, yang diformulasikan sebagai berikut:

Rumus total penerimaan mengacu pada Suratiyah, 2015 sebagai berikut :

Penerimaan $=$ Py $x$ Y

Keterangan :

Py = Harga produk per $\mathrm{Kg}(\mathrm{Rp} / \mathrm{Kg})$

$\mathrm{Y}=$ Jumlah Produksi $(\mathrm{Kg})$

Rumus total biaya ialah sebagai berikut :
$\mathrm{TC}=\mathrm{FC}+\mathrm{VC}$

Keterangan :

$\mathrm{TC}=$ Total Cost (Biaya total) (Rp)

$\mathrm{FC}=$ Fixed Cost (Biaya Tetap Total) $(\mathrm{Rp})$

$\mathrm{VC}=$ Variable Cost (Biaya Variabel Total) (Rp)

Pedapatan $=$ Penerimaan - Biaya total ......(3)

Setelah diperoleh nilai pendapatan petani tebu mitra maupun non mitra, data di uji normalitas dengan uji Kolmogorov-Smirnov. Pengujian normalitas dilakukan untuk mengetahui data yang telah diperoleh apakah berdistribusi normal atau tidak (Hamdi dan Bahruddin, 2014). Uji normalitas mempunyai kriteria pengujian apabila nilai Signifikansi $>$ 0,05 , maka data berdistribusi normal, sedangkan apabila nilai Signifikansi $\leq 0,05$ maka data tidak berdistribusi normal (Nisfiannoor, 2009). Data yang telah di uji normalitasnya di uji dengan uji beda sebagai berikut :

\section{Uji One Sample t Test}

Uji One sample t test dilakukan untuk mengetahui apakah terdapat perbedaan antara rata-rata pendapatan petani tebu mitra dan non mitra per bulan dengan Upah Minimum Kota/Kabupaten (UMK) Kudus. One sample $t$ test merupakan uji yang digunakan untuk mengetahui suatu data dengan asumsi ratarata yang ditentukan (Wahyono, 2012).

\section{Hipotesis}

Ho : $\mu \mathrm{a}=\mu \mathrm{b}$, diduga tidak terdapat perbedaan antara pendapatan petani tebu mitra dan non mitra dengan upah minimum Kabupaten Kudus.

Ha : $\mu \mathrm{a} \neq \mu \mathrm{b}$, diduga terdapat perbedaan antara pendapatan petani tebu mitra dan non mitra dengan upah minimum Kabupaten Kudus.

Keterangan :

$\mu \mathrm{a}=$ Pendapatan petani tebu mitra dan non mitra/bulan

$\mu \mathrm{b}=$ Upah Minimum Kota/Kabupaten (UMK) Kudus 
Uji Independent Sample t Test:

Uji Independent Sample t Test digunakan untuk mengetahui apakah ada perbedaan produksi dan pendapatan antara petani tebu mitra dengan petani tebu non mitra.

\section{Hipotesis}

Ho : $\mu \mathrm{a}=\mu \mathrm{b}$, diduga tidak terdapat perbedaan produksi dan pendapatan antara petani tebu mitra dengan petani non mitra pabrik gula.

Ha : $\mu \mathrm{a} \neq \mu \mathrm{b}$, diduga terdapat perbedaan produksi dan pendapatan antara petani tebu mitra pabrik gula dengan petani non mitra.

Keterangan :

$\mu \mathrm{a}=$ Produksi dan pendapatan tebu petani mitra/ha/tahun.

$\mu \mathrm{b}=$ Produksi dan pendapatan tebu petani non mitra/ha/tahun.

Kriteria penilaian pada aplikasi SPSS untuk kedua uji di atas ialah dengan melihat nilai Sig. (2 tailed), apabila nilainya lebih dari 0,05 maka Ho ditolak dan $\mathrm{Ha}$ diterima, sedangkan apabila nilainya lebih kecil dari 0,05 maka Ho diterima dan Ha ditolak (Santoso, 2010).

\section{HASIL DAN PEMBAHASAN}

\section{Keadaan Umum}

Kabupaten Kudus merupakan salah satu kabupaten di Jawa Tengah yang terletak di antara Kabupaten Jepara, Pati, Demak, dan Grobogan. Luas wilayah Kabupaten Kudus ialah 42.515,64 hektar dengan sebagian besar lahannya ialah lahan pertanian baik sawah $(48,36 \%)$ maupun bukan sawah $(28,61 \%)$, sedangkan sisanya ialah lahan bukan pertanian dengan presentase 23,03\%. Jumlah penduduk di Kabupaten Kudus saat ini tercatat sebesar 851.478 jiwa yang terdiri dari 419.212 laki-laki $(49,23 \%)$ dan 432.266 perempuan $(50,77 \%)$. Kepadatan penduduk di Kabupaten Kudus tercatat sebesar 2.003 jiwa/m² (Badan Pusat Statistik, 2018).
Luas lahan tebu di Kudus pada tahun 2017 tercatat 5.528,99 hektar dengan jumlah produksi 294.031,48 ton. Wilayah dengan lahan tebu terluas dan produksi tebu terbanyak ialah secara berturut-berturut Kecamatan Jekulo, Dawe, dan Gebog. Kecamatan Jekulo memiliki lahan tebu yang terluas di Kabupaten Kudus yaitu sebesar $1.581,20$ ha dengan jumlah produksi $91.027,87$ ton. Lahan tebu yang ada di kecamatan Dawe ialah sebesar 1.510,95 ha dengan jumlah produksi 76.043,59 ton. Luas lahan tebu di Kecamatan Gebog sebesar $1.072,25$ ha dengan jumlah prooduksi $55.824,24$ ton.

Sebagai salah satu penghasil tanaman tebu terbanyak di Jawa Tengah, terdapat salah satu pabrik gula milik BUMN di Kabupaten Kudus yaitu PG. Rendeng. Pabrik gula ini berdiri sejak tahun 1840 dan telah dilakukan revitalisasi pada tahun 2017 lalu. Bentuk kemitraan yang diterapkan ialah dengan melakukan sistem bagi hasil dengan petani mitra, selain itu petani mitra akan mendapatkan beberapa fasilitas. Melalui Koperasi Petani Tebu Rakyat (KPTR) Sari Buana, PG. Rendeng memberikan beberapa fasilitas seperti kepastian penyaluran hasil panen, pinjaman dengan bunga rendah, dan pupuk dengan harga rendah. PG. Rendeng melakukan musim giling pada bulan Mei Juli selama kurang lebih 85 hari.

\section{Profil Responden}

Responden penelitian ini ialah petani tebu mitra dan non mitra dari tiga Kecamatan yang memiliki luas lahan tebu paling tinggi di Kabupaten Kudus yaitu Kecamatan Gebog, Jekulo, dan Dawe. Jumlah responden yang dijadikan sampel ialah sebanyak 60 orang dengan pembagian 30 petani mitra dan 30 petani non mitra. Oleh karena itu pada setiap kecamatan diambil 10 responden petani mitra dan 10 responden petani non mitra. Profil responden terdiri dari usia, tingkat pendidikan, lama bertani, dan kepemilikan lahan. 
Tabel 1. Profil Responden Petani Mitra dan Non Mitra di Kabupaten Kudus

\begin{tabular}{|c|c|c|c|c|c|}
\hline \multirow{2}{*}{ No. } & \multirow{2}{*}{ Profil Responden } & \multicolumn{2}{|c|}{ Petani Mitra } & \multicolumn{2}{|c|}{ Petani Non Mitra } \\
\hline & & Jumlah & Presentase & Jumlah & Presentase \\
\hline & & ---orang--- & -----\%---- & ---orang--- & ----0\%---- \\
\hline \multicolumn{6}{|c|}{ 1. Usia (Tahun) } \\
\hline & $21-30$ & 1 & 3,33 & 1 & 3,33 \\
\hline & $31-40$ & 5 & 16,67 & 4 & 13,33 \\
\hline & $41-50$ & 6 & 20,00 & 10 & 33,33 \\
\hline & $51-60$ & 10 & 33,33 & 15 & 50,00 \\
\hline & $\geq 61$ & 8 & 26,67 & - & - \\
\hline \multicolumn{6}{|c|}{ 2. Tingkat Pendidikan } \\
\hline & $\mathrm{SD}$ & 5 & 16,67 & 12 & 40,00 \\
\hline & SMP & 8 & 26,67 & 8 & 26,67 \\
\hline & SMA & 10 & 33,33 & 9 & 30,00 \\
\hline & Perguruan Tinggi & 7 & 23,33 & 1 & 3,33 \\
\hline \multicolumn{6}{|c|}{ 3. Lama Bertani (tahun) } \\
\hline & $1-10$ & 4 & 13,33 & 4 & 13,33 \\
\hline & $11-20$ & 13 & 43,33 & 12 & 40,00 \\
\hline & $21-30$ & 5 & 16,67 & 9 & 30,00 \\
\hline & $31-40$ & 5 & 16,67 & 5 & 16,67 \\
\hline & $>41$ & 3 & 10,00 & - & - \\
\hline \multicolumn{6}{|c|}{ 4. Kepemilikan Lahan (ha) } \\
\hline & $1-10$ & 16 & 53,33 & 25 & 83,33 \\
\hline & $11-20$ & 7 & 23,33 & 5 & 16,67 \\
\hline & $21-30$ & 6 & 20,00 & - & - \\
\hline & $\geq 31$ & 1 & 3,33 & - & - \\
\hline
\end{tabular}

Sumber : Data Primer Penelitian, 2018.

Berdasarkan Tabel 1 dapat diketahui bahwa responden yang ditemui pada penelitian ini baik petani tebu mitra atau non mitra paling banyak berada pada usia $51-60$ tahun. Jumlah petani tebu mitra yang berada pada rentang usia tersebut ialah 10 orang $(33,33 \%)$, sedangkan petani tebu non mitra ialah 15 orang $(50 \%)$. Rata-rata usia responden petani mitra ialah 52 tahun, sedangkan petani non mitra 49 tahun. Hal tersebut menunjukkan bahwa baik petani tebu mitra atau petani tebu non mitra berada pada usia yang produktif. Menurut Kumbadewi et al. (2016) pada usia produktif, seorang pekerja akan mampu melakukan pekerjaannya dengan lebih baik.

Tingkat pendidikan pada petani tebu cukup beragam. Tingkat pendidikan petani mitra paling banyak berada pada tingkat
SMA, namun pada tingkatan pendidikan lainnya jumlahnya juga cukup seimbang. Untuk petani non mitra tingkatan pendidikan paling banyak berada pada tingkat SD, meskipun begitu banyak pula responden yang telah lulus SMP, SMA, bahkan S1. Tingkat pendidikan petani dianggap dapat mempengaruhi keputusan yang diambil untuk usahataninya ataupun peluang dan keuntungan yang akan diterima (Cahyarubin, 2016).

Petani tebu mitra dan petani non mitra paling banyak memiliki pengalaman bertani tebu selama $11-20$ tahun yaitu petani mitra 13 orang $(43,33 \%)$ dan petani non mitra 12 orang $(40 \%)$. Rata-rata pengalaman bertani petani tebu mitra lebih tinggi yaitu 23 tahun, sedangkan petani tebu non mitra yaitu 21 tahun. Hal tersebut menunjukkan bahwa petani tebu baik mitra maupun non mitra 
memiliki pengalaman bertani yang cukup lama. Menurut Yanutya (2013) semakin lama pengalaman yang dimiliki maka petani akan lebih mengerti dalam mengelola tanaman tebu supaya menghasilkan tebu yang berkualitas dan pendapatan yang maksimal.

Kepemilikan lahan petani tebu mitra mayoritas memiliki lahan $1-10$ hektar yaitu 16 orang $(53,33 \%)$, begitu juga dengan petani tebu non mitra mayoritas memiliki lahan $1-10$ hektar yaitu 25 orang $(83,33 \%)$. Tak sedikit pula petani tebu mitra yang memiliki luas lahan lebih dari 10 hektar $(46,67)$. Sedangkan untuk petani non mitra yang memiliki luas lahan $11-20$ hektar ialah 5 orang $(16,67 \%)$. Petani tebu mitra cenderung memiliki lahan yang lebih luas daripada petani tebu non mitra. Hal tersebut dikarenakan salah satu syarat menjadi petani mitra ialah petani tebu harus memiliki lahan minimal 2 hektar, sedangkan petani non mitra kebanyakan memiliki lahan kurang dari 2 hektar. Hal ini didukung oleh pendapat Priyadi (2008) yang menyatakan bahwa semakin luas lahan yang dimiliki petani tebu maka petani akan mengurangi risiko usahataninya dengan melakukan kemitraan dengan pabrik gula.

\section{Analisis Pendapatan Petani Tebu Mitra dan Non Mitra Analisis Produksi}

Produksi tebu merupakan salah satu faktor yang dapat mempengaruhi besar kecilnya pendapatan yang diterima oleh petani tebu. Berdasarkan penelitian yang telah dilakukan diperoleh hasil produksi usahatani tebu mitra ialah sebesar $1.226 .000 \mathrm{~kg}$, sedangkan untuk usahatani tebu non mitra jumlah produksinya ialah $468.850 \mathrm{~kg}$ dengan luas rerata masing-masing 13,5 hektar dan 5 hektar. Rata-rata luas lahan yang dimiliki petani tebu mitra lebih tinggi daripada petani non mitra, karena untuk dapat bermitra dengan PG Rendeng petani harus memiliki lahan dengan luas minimal 2 hektar. Apabila ditinjau dari produksi tebu per hektar, keduanya memiliki nilai yang tidak terlalu berbeda. Produksi per hektar usahatani tebu mitra ialah sebesar $90.333 \mathrm{~kg}$, sedangkan usahatani non mitra memiliki jumlah produksi per hektar sebesar $89.000 \mathrm{~kg}$. Hal ini sesuai dengan pendapat Naim et al. (2015) pada penelitiannya yang menyatakan bahwa jumlah produksi tebu antara petani mitra dan petani non mitra tidak jauh berbeda. Hal tersebut membuktikan bahwa kemitraan tidak terlalu berpengaruh pada jumlah produksi petani tebu.

\section{Analisis Penerimaan}

Berdasarkan penelitian diperoleh hasil penerimaan petani tebu mitra dan non mitra

Tabel 2. Penerimaan Petani Tebu Mitra dan Non Mitra

\begin{tabular}{lcc}
\hline Keterangan & Petani Mitra & \multicolumn{2}{c}{$\begin{array}{c}\text { Petani Non } \\
\text { Mitra }\end{array}$} \\
\hline $\begin{array}{l}\text { Penerimaan } \\
\text { Tebu }\end{array}$ & --- Rp/ha/tahun--- \\
$\begin{array}{l}\text { Glondong } \\
\text { Penjualan }\end{array}$ & - & 45.826 .667 \\
$\begin{array}{l}\text { Gula } \\
\text { (Pabrik) }\end{array}$ & 39.172 .320 & - \\
Natura & 4.483 .054 & - \\
Tetes Tebu & 4.336 .000 & - \\
\hline $\begin{array}{l}\text { Jumlah } \\
\text { Penerimaan }\end{array}$ & 47.991 .374 & 45.826 .667 \\
\hline
\end{tabular}

Sumber : Data Primer Penelitian, 2018.

sebagai berikut :

Penerimaan petani tebu mitra diperoleh dari sistem bagi hasil penggilingan tebu di pabrik gula yang menghasilkan gula pasir dan produk sampingan berupa tetes tebu. Menurut Ekawati (2013) tebu yang telah diterima oleh pabrik gula akan ditimbang terlebih dahulu, kemudian dilakukan pengolahan menjadi nira dan berakhir menjadi gula. Gula yang dihasilkan terbagi menjadi dua bagian yaitu $90 \%$ dibeli langsung oleh pabrik gula dan sisanya $10 \%$ diserahkan kepada petani sebagai natura, namun biasanya petani menjual natura kepada tengkulak dengan harga yang sedikit lebih tinggi daripada harga lelang dari pabrik gula. Rata-rata total 
penerimaan petani tebu mitra per hektar ialah sebesar Rp 47.991.374,-/ha/tahun. Besar nominal yang diterima petani tebu mitra tergantung dari besarnya rendemen tebu. Hal ini sesuai dengan pendapat Cahyarubin (2016) yang menyatakan penerimaan yang diterima petani mitra ditentukan dari rendemen yang diperoleh.

Petani tebu non mitra memperoleh penerimaan dari hasil penjualan tebu berupa batang (glondong) kepada pengumpul. Besarnya penerimaan petani tebu non mitra tergantung dari harga tebu per kg. Rata-rata penerimaan petani tebu non mitra ialah $\mathrm{Rp}$ 45.826.667,-/ha/tahun. Dengan rata-rata jumlah produksi yang tidak jauh berbeda, penerimaan yang diterima petani tebu non mitra lebih sedikit daripada penerimaan petani tebu mitra.

\section{Analisis Biaya}

Biaya usahatani merupakan nilai korbanan yang dikeluarkan untuk melaksanakan suatu usahatani. Menurut Mustapa (2013), usahatani membutuhkan biaya yang terbagi menjadi dua kelompok yaitu biaya tetap ( $f i x$ cost) dan biaya variabel (variable cost).

Berdasarkan Tabel 3 dapat diketahui bahwa jumlah biaya tetap yang harus dikeluarkan oleh petani tebu mitra dalam satu tahun (musim tanam) yaitu sebesar Rp 9.057.906,-/ha/tahun, sedangkan untuk petani tebu non mitra rata-rata total biaya tetap yang dikeluarkan ialah sebesar Rp 9.410.044,-/ha/tahun. Biaya variabel yang dikeluarkan oleh petani tebu mitra yaitu Rp 23.764.833,-/ha/tahun, sedangkan untuk untuk petani tebu non mitra rata-rata biaya variabel yang dikeluarkan ialah sebesar Rp 25.656.651,-/ha/tahun.

Rata-rata total biaya yang dikeluarkan oleh petani tebu mitra ialah sebesar Rp 32.822.739,-/ha/tahun sedangkan rata-rata total biaya yang dikeluarkan petani non mitra ialah sebesar Rp 35.006.695,-/ha/tahun. Ratarata biaya total petani tebu mitra lebih kecil daripada petani tebu non mitra karena petani tebu mitra mendapatkan pupuk dengan harga yang lebih murah dari PG Rendeng dan bunga kredit yang rendah. Hal tersebut sesuai dengan penelitian Cahyarubin (2016) yang menyatakan bahwa biaya yang keluarkan petani tebu mitra lebih kecil daripada petani non mitra, hal tersebut dikarenakan petani tebu mitra memperoleh fasilitas dari pabrik gula yang dapat meringankan beban biaya yang harus dikeluarkan.

Tabel 3. Biaya Produksi Petani Tebu Mitra dan Non Mitra

\begin{tabular}{|c|c|c|c|}
\hline No. & Keterangan & Petani Mitra & Petani Non Mitra \\
\hline \multirow{7}{*}{1.} & & ---Rp/tahun/ha--- & ---Rp/tahun/ha--- \\
\hline & Biaya Tetap & & \\
\hline & Penyusutan & 116.886 & 45.397 \\
\hline & Bunga Pinjaman & 9.893 & 29.278 \\
\hline & Sewa Lahan & 8.909 .399 & 9.312 .063 \\
\hline & PBB & 21.728 & 23.306 \\
\hline & Jumlah Biaya Tetap & 9.057 .906 & 9.410 .044 \\
\hline \multirow[t]{6}{*}{2.} & Biaya Variabel & & \\
\hline & Pupuk ZA & 1.456 .000 & 2.702 .000 \\
\hline & Pupuk Phonska (NPK) & 1.441 .333 & 1.633 .000 \\
\hline & Upah Tenaga Kerja & 7.317 .500 & 7.324 .984 \\
\hline & Tebang Angkut & 13.550 .000 & 13.996 .667 \\
\hline & Jumlah Biaya Variabel & 23.764 .833 & 25.656 .651 \\
\hline \multicolumn{2}{|c|}{ Total Biaya Produksi } & 32.822 .739 & 35.006 .695 \\
\hline
\end{tabular}

Sumber : Data Primer Penelitian, 2018. 


\section{Analisis Pendapatan}

Berdasarkan penelitian dan perhitungan yang telah dilakukan diperoleh rata-rata pendapatan per hektar petani tebu mitra sebesar Rp 15.168.423,-/ha, sedangkan pendapatan petani tebu non mitra ialah sebesar Rp 10.756.866,-/ha. Pendapatan petani mitra lebih besar daripada pendapatan petani non mitra. Hal tersebut dikarenakan petani tebu mitra mendapatkan jaminan penyaluran panen dan harga. Hal ini sesuai dengan pendapat Utami et al. (2015) yang menyatakan bahwa salah satu manfaat kemitraan untuk petani tebu ialah adanya jaminan pemasaran hasil yang pasti dengan harga yang layak. Petani tebu mitra menyalurkan hasil panennya ke PG Rendeng akan menerima uang setelah tebu diolah menjadi gula, selain itu petani juga mendapatkan pemasukan dari produk samping hasil penggilingan tebu yaitu tetes tebu. Petani mitra mendapatkan nilai tambah (added value) dari hasil penggilingan tebu tidak seperti petani non mitra yang menjual tebunya secara langsung/utuh, sehingga pendapatan yang diperoleh juga lebih tinggi. Hal tersebut sesuai dengan pendapat Isyandi (2007) yang menyatakan bahwa peningkatan nilai tambah di sektor pertanian akan meningkatkan pendapatan para pelakunya.

\section{Komparasi Pendapatan per Bulan dengan Upah Minimum Kabupaten (UMK) Kudus}

Pendapatan merupakan salah satu bentuk keberhasilan suatu usahatani. Hal tersebut sesuai dengan pendapat Purwanti (2007) yang menyatakan bahwa keberhasilan suatu usaatani dapat dilihat dari pendapatan yang dihasilkannya. Sebuah usahatani dikatakan berhasil/baik apabila pendapatan per bulannya sama atau lebih besar dari upah minimum kabupaten/kota setempat. Menurut Zen dan Hutagalung (2007) Upah Minimum Kota/Kabupaten merupakan upah yang besarnya ditentukan oleh Dewan Perupahan di masing-masing kota/kabupaten berdasarkan perhitungan kebutuhan minimum. Oleh karena itu untuk mengetahui baik tidaknya usahatani yang dilakukan oleh petani tebu mitra dan non mitra di Kudus dilakukan analisis komparasi pendapatan petani tebu mitra dan non mitra dengan UMK Kudus. Berdasarkan analisis yang telah dilakukan diperoleh data pada Tabel 4.

Berdasarkan Tabel 4 dapat diketahui bahwa komparasi pendapatan per bulan petani tebu mitra dengan upah minimum Kabupaten Kudus memiliki nilai signifikansi $0,00 \leq 0,05$ artinya Ho ditolak dan Ha diterima. Sehingga dapat disimpulkan bahwa terdapat perbedaan antara pendapatan petani tebu mitra dengan UMK Kudus. Komparasi pendapatan per bulan petani tebu non mitra dengan UMK Kudus memilki nilai signifikansi $0,006 \leq 0,05$ artinya Ho ditolak dan $\mathrm{Ha}$ diterima. Kesimpulannya terdapat perbedaan antara pendapatan per bulan petani tebu non mitra dengan UMK Kudus. Apabila dilihat dari nilai $\mathrm{t}$ hitungnya, keduanya memilki nilai positif. Artinya pendapatan petani tebu baik mitra maupun non mitra lebih tinggi daripada UMK Kudus. Hal ini sesuai dengan penelitian Syakir et al. (2013) yang menyatakan bahwa pendapatan petani tebu di Purbalingga lebih besar daripada UMK baik yang bermitra maupun tidak.

Tabel 4. Hasil Analisis Komparasi Pendapatan Petani Tebu Mitra dan Non Mitra dengan UMK Kabupaten Kudus.

\begin{tabular}{|c|c|c|c|c|c|}
\hline No. & Keterangan & Pendapatan & UMK & Signifikansi & Simpulan \\
\hline \multicolumn{6}{|c|}{----------Rp/bulan--------- } \\
\hline 1. & Petani Mitra & 16.434 .925 & 1802500 & 0,000 & Terdapat Perbedaan \\
\hline 2. & Petani Non Mitra & 4.835 .560 & 1.892 .500 & 0,006 & Terdapat Perbedaan \\
\hline
\end{tabular}

Sumber : Data Primer Penelitian, 2018. 
Tabel 5. Hasil Analisis Komparasi Produksi Tebu Petani Mitra dan Non Mitra.

\begin{tabular}{ccccc}
\hline \hline Keterangan & Petani Mitra & Petani Non Mitra & Signifikansi & Simpulan \\
\hline \multicolumn{5}{c}{------Kg/ha/tahun----- } \\
Produksi Tebu & 90.333 & 89.000 & 0,351 & Tidak Terdapat Perbedaan \\
\hline
\end{tabular}

Sumber : Data Primer Penelitian, 2018.

Tabel 6. Hasil Analisis Komparasi Produksi dan Pendapatan Petani Tebu Mitra dan Non Mitra.

\begin{tabular}{cccccc}
\hline \hline Keterangan & Satuan & Petani Mitra & Petani Non Mitra & Signifikansi & Simpulan \\
\hline Pendapatan & Rp/ha/tahun & 15.166 .604 & 10.844 .639 & 0,000 & Ho ditolak \\
\hline
\end{tabular}

Sumber : Data Primer Penelitian, 2018.

\section{Komparasi Produksi Tebu Petani Mitra dengan Petani Non Mitra}

Berdasarkan analisis yang telah dilakukan dengan bantuan SPSS 16 diperoleh hasil yang disajikan pada Tabel 5 .

Berdasarkan Tabel 5 dapat diketahui bahwa rata-rata produksi tebu memiliki nilai signifikansi $0,351>0,05$ artinya Ho ditolak Ha diterima sehingga dapat disimpulkan bahwa tidak ada perbedaan antara produksi tebu mitra dengan petani tebu non mitra. Hal ini sesuai dengan penelitian Cahyarubin (2016) yang menyatakan bahwa tidak terdapat perbedaan yang signifikan antara produksi tebu petani mitra dan petani non mitra. Ratarata jumlah produksi dari penelitian ini juga hampir sama dengan penelitian Utami et al. (2015) yaitu $80.000-100.000 \mathrm{~kg} / \mathrm{ha}$.

\section{Komparasi Pendapatan Tebu Petani Mitra dengan Petani Non Mitra}

Berdasarkan analisis Independent sample $t$ test dengan bantuan aplikasi SPSS 16 yang telah dilakukan maka diperoleh hasil yang disajikan pada Tabel 6.

Berdasarkan Tabel 6 dapat diketahui bahwa pendapatan per hektar memiliki nilai signifikansi $0,00 \leq 0,05$ artinya Ho ditolak dan Ha diterima sehingga dapat disimpulkan bahwa terdapat perbedaan pendapatan per hektar antara petani tebu mitra dan non mitra. Hal tersebut sesuai dengan hasil penelitian Utami et al. (2015) yang menyatakan bahwa terdapat perbedaan antara pendapatan petani tebu mitra dan petani tebu non mitra.
Pendapatan per hektar per tahun petani tebu mitra lebih tinggi daripada petani tebu non mitra. Hal ini juga sesuai dengan penelitian Cahyarubin (2016) yang menyatakan bahwa pendapatan petani non mitra lebih tinggi daripada petani tebu non mitra yaitu masingmasing Rp 7.228.487,-/ha/tahun dan Rp 351.678,-/ha/tahun.

\section{SIMPULAN DAN SARAN}

\section{Simpulan}

Berdasarkan hasil penelitian dan pembahasan dapat disimpulkan bahwa :

1. Tidak terdapat perbedaan antara produksi petani tebu mitra dan petani tebu non mitra.

2. Terdapat perbedaan antara rata-rata pendapatan per bulan petani tebu mitra maupun non mitra dengan UMK (Upah Minimum Kota/Kabupaten) Kudus.

3. Terdapat perbedaan antara pendapatan petani tebu mitra dan petani tebu non mitra. Petani tebu mitra memiliki pendapatan yang lebih tinggi daripada petani tebu non mitra.

\section{Saran}

Berdasarkan penelitian yang telah dilakukan, saran yang diberikan peneliti ialah :

1. Berdasarkan hasil analisis diharapkan petani tebu dapat melakukan kemitraan dengan pabrik gula supaya mendapatkan kepastian penyaluran panen dan pendapatan yang lebih tinggi. 
2. Pemerintah lebih bijak dalam mengatur penetapan harga gula harga gula tetap stabil supaya kesejahteraan petani tebu terjamin dan tidak mengalami kerugian.

\section{DAFTAR PUSTAKA}

Anriza, S. P. 2017. Kemitraan Antara Petani Tebu dengan Pabrik Gula (Studi Kasus Pada Petani Tebu di Desa Mangli Wetan Kec. Tapen Kab. Bondowoso). Skripsi. Program Sarjana Universitas Airlangga. Surabaya.

Badan Pusat Statistik. 2018. Kabupaten Kudus dalam Angka 2018. Badan Pusat Statistik Kabupaten Kudus. https://kuduskab.bps.go.id/publication/ 2018/08/16/7812ae46f6b77cf56e22b1 f5/kabupaten-kudus-dalam-angka2018.html Diakses pada 17 Oktober 2018 .

Cahyarubin, A. 2016. Analisis Pendapatan Usahatani Tebu Petani Mitra Dan Non Mitra Pg Rejoagung Baru, Kabupaten Madiun. Skripsi. Program Sarjana Institut Pertanian Bogor. Bogor.

Ekawati, M. P. 2013. Analisis Kepuasan Petani Tebu Mitra Terhadap Kemitraan dengan PG Pakis Baru. Skripsi. Program Sarjana Institut Pertanian Bogor. Bogor.

Hamdi, A. S. dan E. Bahruddin. 2014. Metode Penelitian Kuantitatif Aplikasi dalam Pendidikan. Deepublish, Yogyakarta.

Isyandi, B. 2007. Analisis ekonomi usahatani hortikultura sebagai komoditi unggulan agribisnis di daerah Kabupaten Pelalawan Provinsi Riau. J. Bisnis Strategi. 16 (2): 108 - 118.

Kumbadewi, L. S., I. W. Suwendra dan G. P. A. J. Susila. 2016. Pengaruh umur, pengalaman kerja, upah, teknologi dan lingkungan kerja terhadap produktivitas karyawan. J. Bisma Universitas Pendidikan Ganesha. 4 (1): 1-11.
Morissan, M. A. 2012. Metode Penelitian Survei. Kencana, Jakarta.

Mustapa, I. W. 2013. Analisis komparatif pendapatan usahatani kelapa sawit kelompok iga dan plasma di Desa Gunungsari Kecamatan Pasangkayu Kabupaten Mamuju Utara. J. Agrotekbis. 1 (2): 153 - 158.

Naim, S., L. A. Sasongko, dan E. S. Nurjayanti. 2015. Pengaruh kemitraan terhadap pendapatan usahatani tebu (studi kasus di Kecamatan Tayu Kabupaten Pati Provinsi Jawa Tengah). J. Mediagro. 11 (1): 47 - 59.

Nisfiannoor, M. 2009. Pendekatan Statistika Modern untuk Ilmu Sosial. Penerbit Salemba Humanika, Jakarta.

Priyadi, U. 2008. Peranan inovasi kelembagaan Pabrik Gula Madukismo terhadap pelaksanaan usahatani tebu di Propinsi Daerah Istimewa Yogyakarta. Economic J. of Emerging. 13 (2): $1-23$.

Purwanti, R. 2007. Pendapatan petani dataran tinggi Sub Das Malino (studi kasus: Kelurahan Gantarang, Kabupaten Gowa). J. Penelitian Sosial dan Ekonomi Kehutanan. 4 (3): 257 - 269.

Sadikin, I., dan K. Subagyono. 2008. Kinerja beberapa indikator kesejahteraan petani padi di perdesaan Kabupaten Karawang 2008. Balai Pengkajian Pertanian Jawa Barat, Bandung Barat.

Santoso, S. 2010. Statistik Nonparametrik. Elex Media Komputindo, Jakarta.

Singarimbun, M. dan S. Effendi. 2006. Metode Penelitian Survai. LP3ES, Jakarta.

Sugiyono. 2016. Metode Penelitian Kuantitatif dan Kualitatif. Alfabeta, Bandung.

Suratiyah, K. 2015. Ilmu Usahatani (edisi revisi). Penebar Swadaya, Jakarta. 
Suwarto, Y., Octavianty, dan S. Hermawati. 2014. TOP 15 Tanaman Perkebunan. Penebar Swadaya, Jakarta.

Syakir, M., S. Deciyanto, dan S. Damanik. 2013. Analisa usahatan budi daya tebu intensif, studi kasus di Kabupaten Purbalingga. J. Buletin Tanaman Tembakau, Serat \& Minyak Industri. 5 (2): $51-57$.

Utami, S., M. Safii, dan T. Wijono. 2015. Evaluasi pola kemitraan usaha tani tebu (studi pada PTPN X (Persero) PG. Pesantren Baru Kediri). J. Administrasi Bisnis. 2 (2): $1-10$.
Wahyono, T. 2012. Analisis Statistik Mudan dengan SPSS 20. Elex Media Komputindo, Jakarta.

Yanutya, P. A. T. 2013. Analisis pendapatan petani tebu di Kecamatan Jepon Kabupaten Blora. J. Economics Development Analysis. 2 (4): 286 296.

Zen, A. P. M. dan D. Hutagalung. 2007. Panduan Bantuan Hukum di Indonesia. Sentralisme Production, Jakarta. 